\title{
Knowledge and Perceptions of COVID-19 Among Health Care Professionals, Medical Students, and Dental Students in the GCC Region: A Cross-Sectional Correlational Study
}

\author{
Mohammad Abdulwahab (iD) \\ Mohammad Kamal (D) \\ Ahmad M AlAli (iD) \\ Yousif $M$ Husain ${ }^{2}$ \\ Maryam Safar ${ }^{3}$ \\ 'Department of Surgical Sciences, Faculty \\ of Dentistry, Health Sciences Center, \\ Kuwait University, Kuwait City, Kuwait; \\ ${ }^{2}$ Department of Family Medicine, \\ Ministry of Health, Kuwait City, Kuwait; \\ ${ }^{3}$ Faculty of Dentistry, Health Sciences \\ Center, Kuwait University, Kuwait City, \\ Kuwait
}

Purpose: The aim of this study was to assess the levels of awareness and knowledge regarding COVID-19 among healthcare professionals and students in Kuwait and the Gulf Cooperation Council (GCC) region.

Materials and Methods: An online cross-sectional survey using a previously validated questionnaire was used to assess the awareness and knowledge levels of COVID-19 in this study, which was distributed via various online platforms to include as many participants as possible. The study targeted medical doctors, dentists, medical students, and dental students from the GCC region. Participants were at least 18 years old, voluntarily consented to complete the questionnaire, and were assured that their responses would remain anonymous. Permission was obtained using a previously validated and applied questionnaire to assess their level of awareness and knowledge regarding COVID-19. To compare the proportional responses between groups in descriptive statistics, a proportion Z-test was used to find any significant differences, with a statistical significance set at $\mathrm{p}<0.05$.

Results: A total of 1621 participants responded to our questionnaire. Almost two-thirds of the respondents were female $(64.4 \%)$, and the majority were less than 25 years old $(67.2 \%)$. Dentists accounted for $12.6 \%$ of the total population, and their clinical experience ranged from 0.25 to 52 years (median: 3 years, IQR: $1-10$ years). Meanwhile, medical doctors accounted for $24.5 \%$ of the responses, and their clinical experience ranged from 0 to 50 years (median: 13 years, IQR: 3-23 years). Among the dental students, 42.3\% were in the preclinical years, while $57.7 \%$ were in the clinical years of study. However, among medical students, $57.5 \%$ were in the pre-clinical years, while $42.5 \%$ were in the clinical years of study.

Conclusion: Our results demonstrated that dental students, medical doctors, and medical students exhibited higher odds of having satisfactory COVID-19 perception scores than dentists.

Keywords: coronavirus, SARS-CoV-2, pandemic, COVID-19, knowledge, perception, healthcare, survey, healthcare worker, medical students

\section{Introduction}

The outbreak of coronavirus SARS-CoV-2 (COVID-19) in Wuhan (China) last December 2019 exceeded previous virus outbreaks, such as severe acute respiratory syndrome coronavirus (SARS-CoV) and Middle East respiratory syndrome coronavirus (MERS-CoV), spreading globally with a great impact on social life. ${ }^{1-3}$ In
Correspondence: Mohammad Abdulwahab Department of Surgical Sciences, Faculty of Dentistry, Health Sciences Center, Kuwait University, Safat, Kuwait City, I2027, Kuwait Email mohammad.abdulwahab@ku.edu.kw 
fact, more than 152,200,000 COVID-19 cases and more than 3,192,000 deaths have been reported worldwide as of May 2, 2021. ${ }^{4}$ To prevent further virus spread and to flatten the infection curve, curfews and restrictions on social activities have been recommended and implemented in most countries. ${ }^{5}$ As a result, global economies have been shut down, schools and higher education have been suspended, and stricter modifications to daily practices particularly within the medical/dental fields have been implemented. For instance, saliva as a biofluid has been shown to be a major transmission medium through the generation of aerosols, prompting the use of proper modifications to lower disease transmission risk. ${ }^{6}$ Another emerging modification during the pandemic was the implementation of teledentistry, which has been widely utilized to remotely assess and triage patients to minimize exposure. $^{7}$

The effect of the COVID-19 pandemic has been vast, and ramifications on health care systems, educational systems, economic structures, trade and finance, and our societies remain catastrophic. ${ }^{8}$ Due to the nature of medical and dental education, major challenges are to be expected in the post-pandemic era. ${ }^{9-11}$ Thus, many issues and arrangements need to be considered for medical and dental educators, healthcare professionals, and students to cope with the possible intensive teaching curricula.

Many studies have investigated the mental status of students and healthcare professionals by evaluating their anxiety and stress levels in response to clinical learning and practice modifications. ${ }^{12-14}$ Moreover, many studies have evaluated their knowledge and awareness regarding COVID-19 according to WHO's information database. ${ }^{15-18}$ However, despite the large number of studies, there is still a gap in literature on the knowledge and awareness of students and healthcare professionals in Kuwait and the Gulf Cooperation Council (GCC) region. Therefore, the aim of this study was to assess the levels of awareness and knowledge regarding COVID-19 among healthcare professionals and students in the aforementioned areas.

\section{Materials and Methods Research Design and Setting}

An online cross-sectional survey was conducted using Google Forms, which the participants completed between May 15 and June 28, 2020. The study aimed to target all healthcare professionals and students in the following categories - dental and medical students, dentists, and medical doctors - from the Gulf Cooperation Council (GCC), which includes Kuwait, the Kingdom of Saudi Arabia, the Kingdom of Bahrain, the United Arab Emirates, and Qatar.

\section{Research Instrument and Data Collection}

Permission was obtained using a previously validated and applied questionnaire to assess the awareness and knowledge levels of COVID-19. ${ }^{19,20}$ The Google Forms survey was distributed via e-mails, WhatsApp groups, and other social media platforms. The URL of the online survey is accessible through https://drive.google.com/file/d/ 1SQqGu7kSx7-19iSlmE1fS1cYnGnscl6y.

\section{Ethical Considerations}

Ethical approval was obtained from the Kuwait University Health Sciences Center Ethical Committee on June 13, 2020, according with the Declaration of Helsinki. Participants who voluntarily consented to complete the questionnaire were required to at least be 18 years old. All participants in the electronic survey accepted participation by selecting to participate prior to enrolment in the survey and were assured that their responses would remain anonymous.

\section{Statistical Analysis}

To compare the proportional responses between groups in descriptive statistics, a proportion Z-test was used to find any significant differences, with a statistical significance set at $\mathrm{p}<0.05$.

Statistical analyses were performed using SPSS version 23 (IBM Corp. Released 2015. IBM SPSS Statistics for Macintosh, Version 23.0. Armonk, NY: IBM Corp.). Survey responses are outlined in the following tables, wherein knowledge and perception scores were considered satisfactory if $>70 \%$ of the questions in each group were answered correctly. Categorical data are presented as counts and percentages and were compared using either the chi-square test or Fisher's exact test (when cell counts $<5)$. Meanwhile, continuous data are presented as medians and interquartile ranges (IQR) and were compared using either the Mann-Whitney $U$-test or Kruskal-Wallis $H$-test (if the data were abnormally distributed). Normally distributed continuous data are presented as mean $( \pm$ standard deviation) and were compared using either Student's $t$-test or the analysis of variance test. 
Univariate and multivariate logistic regression analyses were performed to examine the associations between satisfactory knowledge and perception scores, and demographic variables. The multivariate analysis covariates included gender, age group, profession, country, whether they had heard about COVID-19, and whether they had attended any lectures/discussions on COVID-19, which were all selected a priori. These results are presented as odds ratios (ORs) and 95\% confidence intervals (95\% CIs), with a statistical significance set at $\mathrm{p}<0.05$.

\section{Results}

\section{Demographics}

In total, 1621 participants responded to the questionnaire. Of these, 19 were excluded since the respondents were not dentists, dental students, medical doctors, or medical students, and an additional 23 individuals were excluded due to incomplete information regarding their country of residence or profession. Therefore, only 1579 responses were included in the final analysis.

Table 1 outlines the demographic variables of the study population. Almost two-thirds of the respondents were female $(64.4 \%)$, and the majority were less than 25 years old (67.2\%). Dentists accounted for $12.6 \%$ of the total population, and their clinical experience ranged from 0.25 to 52 years with a median of 3 years (IQR: $1-10$ years). Meanwhile, medical doctors accounted for $24.5 \%$ of the responses, and their clinical experience ranged from 0 to 50 years with a median of 13 years (IQR: 3-23 years). Among the dental students, $42.3 \%$ were in the pre-clinical years, while $57.7 \%$ were in the clinical years of study. On the other hand, among medical students, $57.5 \%$ were in the pre-clinical years, while $42.5 \%$ were in the clinical years of study.

Among the areas within the GCC, Kuwait (44.5\%), the Kingdom of Saudi Arabia (23.9\%), and the Kingdom of Bahrain (19.2\%) were the most represented countries in this survey, with fewer respondents living in the United
Table I Demographics

\begin{tabular}{|l|c|}
\hline Variable & $\mathbf{n}=1579$ \\
\hline Gender & \\
Male & $562(35.6 \%)$ \\
Female & $1017(64.4 \%)$ \\
\hline Age Group & \\
$<25$ years & $1061(67.2 \%)$ \\
$25-44$ years & $356(22.5 \%)$ \\
$\geq 45$ years & $162(10.3 \%)$ \\
\hline Profession & \\
Dentist & $199(12.6 \%)$ \\
Dental Student & $222(14.1 \%)$ \\
Medical Doctor & $387(24.5 \%)$ \\
Medical Student & $771(48.8 \%)$ \\
\hline Location & \\
Kuwait & $702(44.5 \%)$ \\
Kingdom of Saudi Arabia & $378(23.9 \%)$ \\
Kingdom of Bahrain & $303(19.2 \%)$ \\
United Arab Emirates & $104(6.6 \%)$ \\
Oman & $60(3.8 \%)$ \\
Qatar & $32(2.0 \%)$ \\
\hline Heard about COVID-I9 & $1523(96.5 \%)$ \\
Yes & $56(3.5 \%)$ \\
No & $950(60.2 \%)$ \\
\hline Attended Lectures or Discussions about COVID-19 & $629(39.8 \%)$ \\
Yes & \\
No & \\
\hline & \\
\hline & \\
\hline & \\
\hline
\end{tabular}

Arab Emirates (6.6\%), Oman (3.8\%), and Qatar (2\%). Furthermore, almost all respondents $(96.5 \%)$ have heard about COVID-19 at the time of the survey, while only $60.2 \%$ had attended a discussion or lecture about the virus.

\section{Source of Information}

Table 2 outlines the main sources cited by respondents as their source for reliable COVID-19 information, showing government websites (47.1\%) and social media websites $(39.8 \%)$ as the most used ones. Traditional news media

Table 2 Respondent Sources of Reliable Information About COVID-19 ( $=$ 1579)

\begin{tabular}{|l|c|c|c|c|}
\hline Response & News Media, n (\%) & Social Media, n (\%) & Government Websites, n (\%) & Family and Friends, n (\%) \\
\hline Least used & $373(23.6 \%)$ & $211(13.4 \%)$ & $110(7.0 \%)$ & $532(33.7 \%)$ \\
\hline Sometimes & $536(33.9 \%)$ & $386(24.4 \%)$ & $231(14.6 \%)$ & $612(38.8 \%)$ \\
\hline More often & $421(26.7 \%)$ & $354(22.4 \%)$ & $495(31.3 \%)$ & $285(18.0 \%)$ \\
\hline Most used & $249(15.8 \%)$ & $628(39.8 \%)$ & $743(47.1 \%)$ & $150(9.5 \%)$ \\
\hline
\end{tabular}


Table 3 Survey Responses of Dentists, Dental Students, Medical Doctors, and Medical Students Regarding Knowledge of COVID-19

\begin{tabular}{|c|c|c|c|c|c|c|}
\hline & $\begin{array}{c}\text { Total } \\
(\mathrm{n}=\text { I 579) }\end{array}$ & $\begin{array}{l}\text { Dentists } \\
(\mathrm{n}=199)\end{array}$ & $\begin{array}{c}\text { Dental Students } \\
\text { (n = 222) }\end{array}$ & $\begin{array}{l}\text { Medical Doctors } \\
\qquad(n=387)\end{array}$ & $\begin{array}{l}\text { Medical Students } \\
\qquad(n=77 I)\end{array}$ & p-value \\
\hline \multicolumn{7}{|c|}{ What is the incubation period of Novel coronavirus? (Correct Answer: 2-14 days) } \\
\hline Correct & $820(51.9 \%)$ & 97 (48.7\%) & $108(48.6 \%)$ & $180(46.5 \%)$ & $435(56.4 \%)$ & 0.006 \\
\hline Incorrect & 759 (48.1\%) & $102(51.3 \%)$ & $114(51.4 \%)$ & $207(53.5 \%)$ & $336(43.6 \%)$ & \\
\hline \multicolumn{7}{|c|}{ Symptoms of novel coronavirus (SAR-COV-19) are all except? (Correct Answer: Skin Rash) } \\
\hline Correct & $1183(74.9 \%)$ & $122(61.3 \%)$ & $152(68.5 \%)$ & $293(75.7 \%)$ & $616(79.9 \%)$ & $<0.001$ \\
\hline Incorrect & $396(25.1 \%)$ & 77 (38.7\%) & 70 (31.5\%) & $94(24.3 \%)$ & $155(20.1 \%)$ & \\
\hline \multicolumn{7}{|c|}{ Novel Coronavirus (SAR-COV-19) origin is thought to be from? (Correct Answer: Bats) } \\
\hline Correct & 1252 (79.3\%) & 146 (73.4\%) & I 76 (79.3\%) & 305 (78.8\%) & 625 (8I.1\%) & 0.123 \\
\hline Incorrect & 327 (20.7\%) & $53(26.6 \%)$ & 46 (20.7\%) & $82(21.2 \%)$ & 146 (18.9\%) & \\
\hline \multicolumn{7}{|c|}{ Novel Coronavirus (SAR-COV-19) transmission occur through? (Correct Answer: All of the above) } \\
\hline Correct & 485 (30.7\%) & 66 (33.2\%) & 62 (27.9\%) & $130(33.6 \%)$ & 227 (29.4\%) & 0.325 \\
\hline Incorrect & 1094 (69.3\%) & $133(66.8 \%)$ & $160(72.1 \%)$ & 257 (66.4\%) & 544 (70.6\%) & \\
\hline \multicolumn{7}{|c|}{ What are the complications with Novel Coronavirus (SAR-COV-19)? (Correct Answer: All of the above) } \\
\hline Correct & 1406 (89.0\%) & 174 (87.4\%) & 198 (89.2\%) & 372 (96.1\%) & $662(85.9 \%)$ & $<0.001$ \\
\hline Incorrect & $173(11 \%)$ & 25 (12.6\%) & $24(10.8 \%)$ & 15 (3.9\%) & $109(14.1 \%)$ & \\
\hline \multicolumn{7}{|c|}{ What is the treatment for Novel coronavirus (SAR-COV-19)? (Correct Answer: Supportive Care) } \\
\hline Correct & $|36|$ (86.2\%) & 179 (89.9\%) & 181 (8I.5\%) & 357 (92.2\%) & 644 (83.5\%) & $<0.001$ \\
\hline Incorrect & $218(13.8 \%)$ & $20(10.1 \%)$ & $4 \mathrm{I}(18.5 \%)$ & $30(7.8 \%)$ & 127 (16.5\%) & \\
\hline \multicolumn{7}{|c|}{ How to reduce the risk of transmission? (Correct Answer: All of the above) } \\
\hline Correct & 1310 (83.0\%) & I54 (77.4\%) & I 77 (79.7\%) & 321 (82.9\%) & $658(85.3 \%)$ & 0.028 \\
\hline Incorrect & $269(17 \%)$ & 45 (22.6\%) & $45(20.3 \%)$ & $66(17.1 \%)$ & $113(14.7 \%)$ & \\
\hline \multicolumn{7}{|l|}{ Knowledge } \\
\hline Score & $5.0( \pm \mid .2)$ & $4.7( \pm \mid .2)$ & $4.7( \pm I .3)$ & $5.06( \pm I . I)$ & $5.02( \pm I . I)$ & $<0.001$ \\
\hline Satisfactory & 1062 (67.3\%) & $103(51.8 \%)$ & 132 (59.5\%) & 272 (70.3\%) & $555(72 \%)$ & $<0.001$ \\
\hline Unsatisfactory & 517 (32.7\%) & 96 (48.2\%) & 90 (40.5\%) & II (29.7\%) & $216(28 \%)$ & \\
\hline
\end{tabular}

was also cited, while family and friends were accounted as the least used source of reliable information.

\section{Knowledge of COVID-19}

Table 3 presents the responses of dentists, dental students, medical doctors, and medical students pertaining to the knowledge portion of the COVID-19 questionnaire. Medical students were the only group wherein more than half of the respondents knew the correct COVID-19 incubation period $(\mathrm{p}=0.006)$, and medical doctors and medical students were better able to identify COVID-19 symptoms $(\mathrm{p}<0.001)$ than dentists and dental students. All groups scored reasonably well regarding the suspected origins of COVID-19 being bats $(p=0.123)$, and all groups were similarly poor in their responses regarding COVID-19 transmission ( $\mathrm{p}=0.325)$. Moreover, medical doctors were most aware of the potential COVID-19 complications $(\mathrm{p}<0.001)$, while medical doctors and dentists were similarly knowledgeable regarding COVID-19 treatment when compared with the student groups ( $p<0.001)$. Notably, medical students scored the highest regarding methods of reducing COVID-19 transmission ( $\mathrm{p}=$ 0.028). Overall, medical doctors and medical students exhibited higher median knowledge scores $(5.06 \pm 1.1$ and $5.02 \pm 1.1$, respectively) than dentists and dental students $(4.7 \pm 1.2$ and $4.7 \pm 1.3$, respectively) ( $p$ $<0.001)$. Medical doctors and medical students also had significantly higher rates of satisfactory knowledge scores 
than dentists and dental students $(\mathrm{p}<0.001)$. Table 4 presents this similar information, but these are analyzed based on gender, age group, and country. Males and females displayed similar levels of satisfactory COVID19 knowledge $(\mathrm{p}=0.117)$, with males having slightly higher raw scores $(5.0 \pm 1.3$ vs $4.9 \pm 1.1, \mathrm{p}=0.026)$. Regarding age, no significant difference was observed between the various age groups in terms of satisfactory knowledge $(p=0.055)$. Among the countries, respondents from the United Arab Emirates performed the poorest in terms of adequate COVID-19 knowledge, with only $38.5 \%$ receiving a satisfactory score $(\mathrm{p}<0.001)$.

\section{Perceptions of COVID-19}

In general, respondents answered the perceptions portion of the questionnaire more successfully than the knowledge section, with $97.2 \%$ of all respondents scoring $>70 \%$. Overall, medical doctors scored the highest $(p<0.001)$ and had the highest proportion of satisfactory scores (98.2\%), while dentists scored the lowest proportion of satisfactory perception scores $(\mathrm{p}=0.003)$. Table 5 outlines the differences in perception responses according to gender, age, and country. Notably, there were no significant differences between the proportion of satisfactory perception scores for either sex $(p=0.914)$ or age group $(p=$ 0.055). Compared to the other countries, the United Arab Emirates once again scored lowest for respondents' perception of COVID-19 in this questionnaire $(p=0.017)$.

Univariate and multivariate logistic regression analysis results in relation to satisfactory knowledge scores and demographic variables are presented in Table 6 . No differences were observed between the sexes in either the univariate or multivariate analyses, and the 25-44 age group had the lowest odds for achieving satisfactory knowledge among the other age groups (univariate OR: $0.74,95 \% \mathrm{CI}$ : $0.57-0.95, \mathrm{p}=0.016$ and multivariate OR: $0.58,95 \% \mathrm{CI}$ : $0.35-0.94, p=0.029)$. For the professional groups, there was no significant difference between dentists and dental students in terms of knowledge; however, medical doctors had greater odds of achieving satisfactory knowledge scores (multivariate OR: 2.76, 95\% CI: 1.85-4.12, $\mathrm{p}<0.001$ ) than medical students (multivariate OR: 2.11, 95\% CI: $1.28-3.48, \mathrm{p}=0.003)$. Regarding countries, there was no significant difference between the respondents from Kuwait and Oman; however, respondents from the Kingdom of Saudi Arabia scored higher (multivariate OR: $1.63,95 \% \mathrm{CI}: 1.20-2.21, \mathrm{p}=0.002$ ), while those from the Kingdom of Bahrain, the United Arab Emirates, and Qatar performed more poorly $(\mathrm{p}=0.044, \mathrm{p}<0.001$, and $\mathrm{p}=$ 0.004 , respectively). Having heard about and attending lectures/discussions about COVID-19 also predicted higher odds of satisfactory knowledge scores $(\mathrm{p}=0.010$ and $\mathrm{p}<0.001$, respectively).

Dental students (multivariate OR: 5.56, 95\% CI: $1.21-$ 25.63, $\mathrm{p}=0.028$ ), medical doctors (multivariate OR: 3.75, 95\% CI: 1.25-11.24, $\mathrm{p}=0.018$ ), and medical students (multivariate OR: 4.61, 95\% CI: $1.22-17.40, \mathrm{p}=0.024$ ) achieved higher odds of having satisfactory perception scores in relation to COVID-19 than dentists.

\section{Discussion}

The COVID-19 pandemic continues to have devastating medical, social, and economic impacts, posing significant challenges for healthcare professionals worldwide. As of late October 2020, there have been more than 152 million confirmed COVID-19 cases and more than 3 million deaths since the start of the outbreak. ${ }^{4}$ Additionally, multiple SARS-CoV-2 variants are being discovered through viral sequencing around the world, raising more concerns about their clinical impact. ${ }^{21}$ Unsurprisingly, new information about COVID-19 is available on a daily basis according to new trials, observations, and clinical data. Therefore, healthcare professionals (as main frontline workers) are obliged to learn about and be aware of emerging evidence and updates regarding this novel disease. However, in that same regard, they should be fully aware of the inflating COVID-19 misinformation as well as research methodological flaws, which are being evident recently. $^{22}$ Therefore, this study showed certain variations in the awareness and knowledge levels of COVID-19 among healthcare professionals and students in Kuwait and the GCC region.

This study revealed that medical doctors and students generally had significantly higher median knowledge scores and satisfactory knowledge rates than dentists and dental students $(\mathrm{p}<0.001)$. While there was no significant difference between dentists and dental students in terms of knowledge, medical doctors and medical students had greater odds of achieving satisfactory knowledge scores ( $p<0.001$ and $p=0.003$, respectively). In addition, higher odds of satisfactory knowledge scores were predicted when respondents had heard about or attended COVID19 lectures or discussions $(\mathrm{p}=0.010$ and $\mathrm{p}<0.001$, respectively). Interestingly, this study indicated that approximately $52 \%$ of the participants responded correctly regarding the COVID-19 incubation period, while 


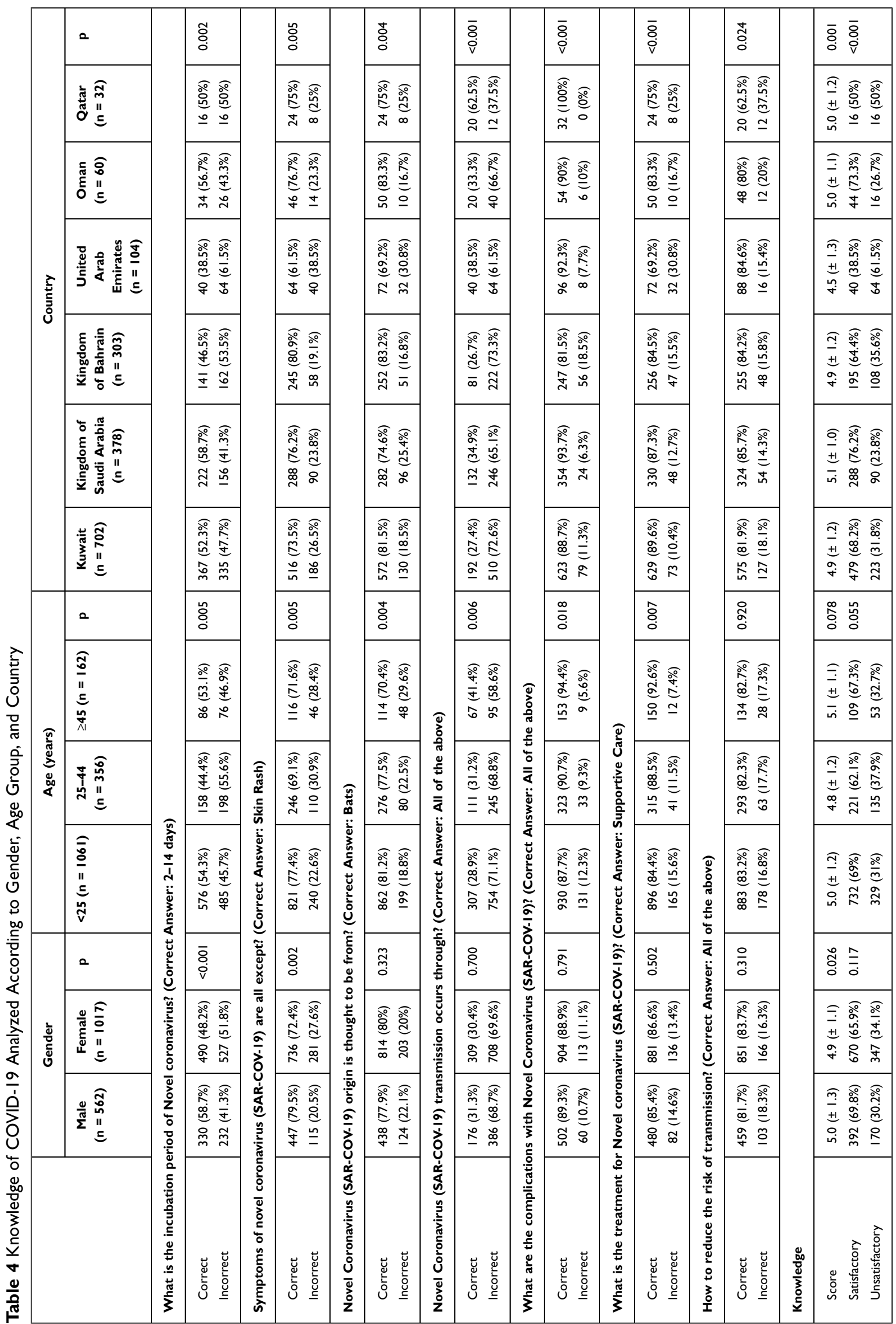




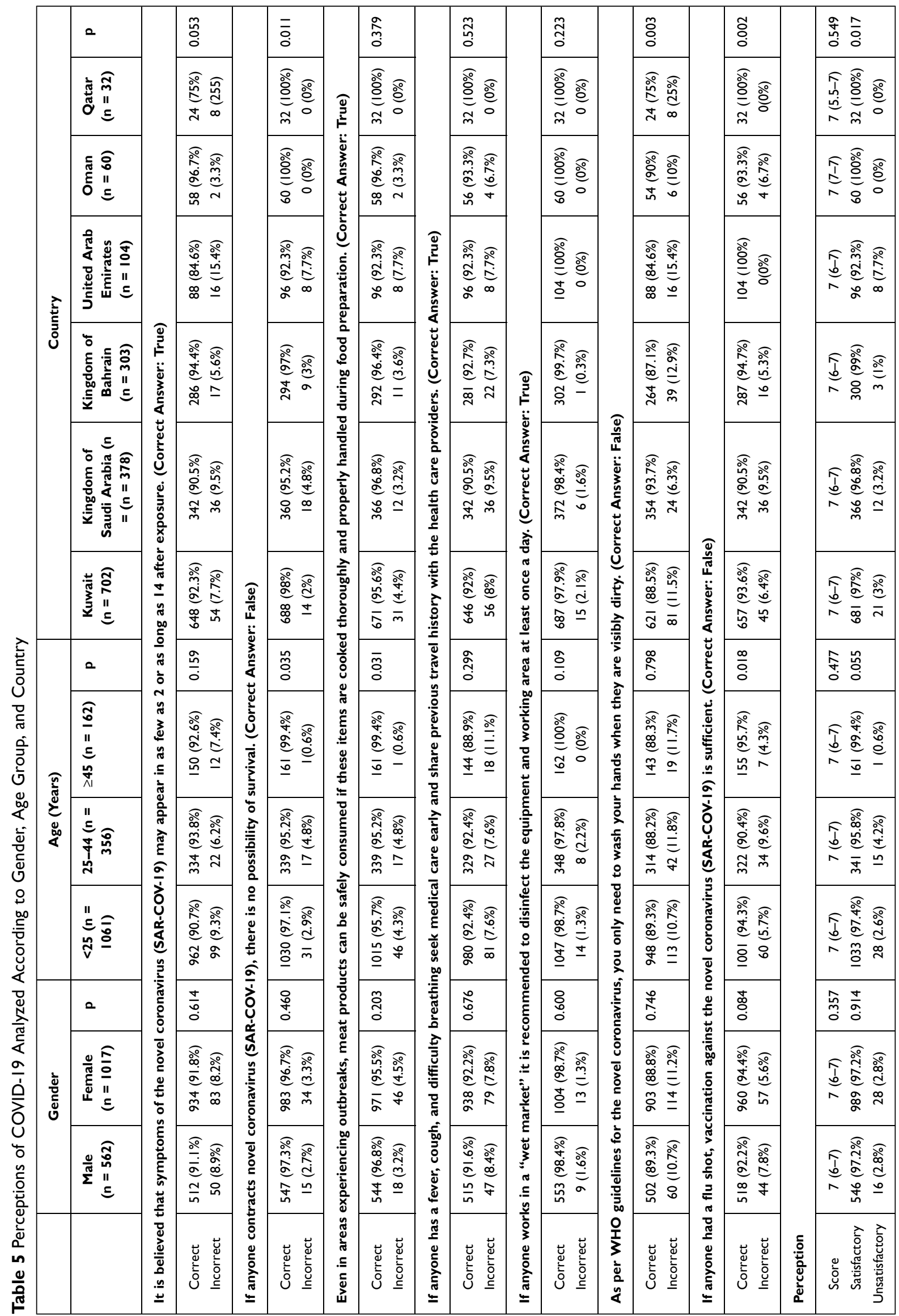


Table 6 Univariate and Multivariate Logistic Regression Between Satisfactory Knowledge and Demographic Variables

\begin{tabular}{|c|c|c|c|c|}
\hline Variable & Univariate OR $(95 \% \mathrm{Cl})$ & p-value & Multivariate OR $(95 \% \mathrm{Cl})$ & p-value \\
\hline \multicolumn{5}{|l|}{ Gender } \\
\hline Male & I. 0 (ref.) & & I. 0 (ref.) & \\
\hline Female & $0.84(0.67-1.05)$ & 0.117 & $0.89(0.70-1.14)$ & 0.374 \\
\hline \multicolumn{5}{|l|}{ Age group } \\
\hline$<25$ years & I.0 (ref.) & & I.0 (ref.) & \\
\hline $25-44$ years & $0.74(0.57-0.95)$ & 0.016 & $0.58(0.35-0.94)$ & 0.029 \\
\hline$\geq 45$ years & $0.92(0.65-1.32)$ & 0.662 & $0.64(0.34-1.20)$ & 0.166 \\
\hline \multicolumn{5}{|l|}{ Profession } \\
\hline Dentist & I.0 (ref.) & & I.0 (ref.) & \\
\hline Dental Student & $1.37(0.93-2.01)$ & 0.113 & $\mathrm{I} .44(0.8 \mathrm{I}-2.54)$ & 0.211 \\
\hline Medical Doctor & $2.20(1.55-3.14)$ & $<0.001$ & $2.76(1.85-4.12)$ & $<0.001$ \\
\hline Medical Student & $2.40(1.74-3.30)$ & $<0.001$ & $2.11(1.28-3.48)$ & 0.003 \\
\hline \multicolumn{5}{|l|}{ Country } \\
\hline Kuwait & I.0 (ref.) & & I.0 (ref.) & \\
\hline Kingdom of Saudi Arabia & $1.49(1.12-1.98)$ & 0.006 & $1.63(1.20-2.21)$ & 0.002 \\
\hline Kingdom of Bahrain & $0.84(0.63-I .12)$ & 0.230 & $0.73(0.54-0.99)$ & 0.044 \\
\hline United Arab Emirates & $0.29(0.19-0.45)$ & $<0.001$ & $0.23(0.15-0.37)$ & $<0.001$ \\
\hline Oman & $\mathrm{I} .28(0.7 \mathrm{I}-2.32)$ & 0.415 & $1.27(0.69-2.34)$ & 0.434 \\
\hline Qatar & $0.47(0.23-0.95)$ & 0.035 & $0.33(0.15-0.70)$ & 0.004 \\
\hline \multicolumn{5}{|l|}{ Heard about COVID-19 } \\
\hline Yes & $2.29(1.33-3.89)$ & 0.003 & $2.06(1.19-3.58)$ & 0.010 \\
\hline No & I.0 (ref.) & & I.0 (ref.) & \\
\hline \multicolumn{5}{|c|}{ Attended Lectures or Discussions about COVID-19 } \\
\hline Yes & $1.43(1.16-1.77)$ & 0.001 & $1.56(1.23-1.98)$ & $<0.001$ \\
\hline No & I. 0 (ref.) & & I. 0 (ref.) & \\
\hline
\end{tabular}

approximately $36 \%$ of healthcare professionals correctly responded to the same question in other studies. ${ }^{18,20}$ These figures clearly demonstrate that different healthcare workers may have insufficient COVID-19 knowledge, which could result in delayed diagnoses, disease transmissions, and poor infection control practices. ${ }^{23,24}$ For instance, only $30.7 \%$ of respondents correctly identified all of the SARSCoV-2 transmission routes (air, contact, and feco-oral). Being aware of its nature is crucial, as the potential risk of SARS-CoV-2 transmission associated with aerosolgenerating procedures places healthcare professionals and students at greater risk, especially in the dental field. ${ }^{25,26}$ Thus, focusing on improving the level of knowledge among healthcare professionals and students should be prioritized, as a positive linear correlation has been found between knowledge and attitudes toward COVID-19. ${ }^{27,28}$ On the other hand, responses about COVID-19 perceptions generally yielded better satisfactory scores than the knowledge scores in this study, wherein medical doctors scored the highest $(p<0.001)$, while dentists had the lowest proportion of satisfactory perception scores $(\mathrm{p}=$ 0.003). Additionally, statistical analyses showed that dental students $(\mathrm{p}=0.028)$, medical doctors $(\mathrm{p}=0.018)$, and medical students $(p=0.024)$ exhibited higher odds of having satisfactory COVID-19 perception scores than dentists.

Bhagavathula et $\mathrm{al}^{20}$ argued that the superior knowledge and perception of medical doctors might be attributed to the more rigorous education on infectious diseases and pharmacotherapy for continued professional development when compared with that of other healthcare professionals, which is a debatable claim. Looking into the COVID-19 information resources, this study found that government (47.1\%) and social media websites (39.8\%) were accounted as the most used channels of information by healthcare professionals. Although social media provides 
a great opportunity for disseminating the latest COVID-19 information, it is also a platform that promotes misinformation and fake news. ${ }^{29,30}$ Critically appraising COVID19 information on social media to ensure validity and credibility should always be implemented as a part of evidence-based practice by healthcare professionals. Further, the findings of this study suggest that there are certain limitations related to COVID-19 knowledge that warrant further investigation and education.

\section{Limitations of the Study}

One of the study's limitations was that it only targeted medical and dental professionals and students, foregoing to include nursing personnel. Another limitation was the low number of participants yielded from some countries, which may have altered their inferences and affected our findings.

\section{Conclusion}

Our results demonstrated that dental students, medical doctors, and medical students exhibited higher odds of having satisfactory COVID-19 perception scores than dentists. This conclusion provides us with evidence that more educational materials should be provided to improve their awareness to a satisfactory level.

\section{Abbreviations}

COVID-19, coronavirus disease 2019; GCC, Gulf Council Countries; SPSS, Statistical Package for Social Sciences; WHO, World Health Organization.

\section{Data Sharing Statement}

The raw data is available via this URL: https://drive.goo gle.com/file/d/1 QOqUad-

IPrmKMKiCFG9AoFbW0mtwptv.

\section{Author Contributions}

All authors made a significant contribution to the work reported, whether that is in the conception, study design, execution, acquisition of data, analysis and interpretation, or in all these areas; took part in drafting, revising or critically reviewing the article; gave final approval of the version to be published; have agreed on the journal to which the article has been submitted; and agree to be accountable for all aspects of the work.

\section{Disclosure}

The authors report no conflicts of interest in this work.

\section{References}

1. Sun P, Lu X, Xu C, Sun W, Pan B. Understanding of COVID-19 based on current evidence. J Med Virol. 2020;92:548-551. doi:10.1002/jmv.25722

2. Wang LS, Wang YR, Ye DW, Liu QQ. A review of the 2019 Novel Coronavirus (COVID-19) based on current evidence. Int J Antimicrob Agents. 2020;55:105948. doi:10.1016/j.ijantimicag.2020.105948

3. Giwa AL, Desai A, Duca A. Novel 2019 coronavirus SARS-CoV-2 (COVID-19): an updated overview for emergency clinicians. Emerg Med Pract. 2020;22:1-28.

4. Center JHCR. COVID-19 global map; 2021. Available from: https:// coronavirus.jhu.edu/map.html. Accessed May 19, 2021.

5. Shim E, Tariq A, Choi W, Lee Y, Chowell G. Transmission potential and severity of COVID-19 in South Korea. Int $J$ Infect Dis. 2020;93:339-344. doi:10.1016/j.ijid.2020.03.031

6. Khurshid Z, Asiri FYI, Al Wadaani H. Human saliva: non-invasive fluid for detecting Novel Coronavirus (2019-nCoV). Int $J$ Environ Res Public Health. 2020;17:2225. doi:10.3390/ijerph17072225

7. Abbas B, Wajahat M, Saleem Z, Imran E, Sajjad M, Khurshid Z. Role of teledentistry in COVID-19 pandemic: a nationwide comparative analysis among dental professionals. Eur J Dent. 2020;14:S116S22. doi:10.1055/s-0040-1722107

8. Sahu KK, Kumar R. Current perspective on pandemic of COVID-19 in the United States. J Family Med Prim Care. 2020;9:1784-1791. doi:10.4103/jfmpc.jfmpc_424_20

9. Ahmed H, Allaf M, Elghazaly H. COVID-19 and medical education. Lancet Infect Dis. 2020;20:777-778. doi:10.1016/S1473-3099(20) 30226-7

10. Meng L, Hua F, Bian Z. Coronavirus disease 2019 (COVID-19): emerging and future challenges for dental and oral medicine. J Dent Res. 2020;99:481-487. doi:10.1177/0022034520914246

11. Rose S. Medical student education in the time of COVID-19. JAMA. 2020;323:2131. doi:10.1001/jama.2020.5227

12. Chew NW, Lee GK, Tan BY, et al. A multinational, multicentre study on the psychological outcomes and associated physical symptoms amongst healthcare workers during COVID-19 outbreak. Brain Behav Immun. 2020;88:559-565. doi:10.1016/j.bbi.2020.04.049

13. Odriozola-González P, Planchuelo-Gómez Á, Irurtia MJ, de Luisgarcía R. Psychological effects of the COVID-19 outbreak and lockdown among students and workers of a Spanish university. Psychiatry Res. 2020.

14. Tan BY, Chew NW, Lee GK, et al. Psychological impact of the COVID-19 pandemic on health care workers in Singapore. Ann Intern Med. 2020;173:317-320. doi:10.7326/M20-1083

15. Kashid RV, Shidhore AA, Kazi MM, Patil S. Awareness of COVID19 amongst undergraduate dental students in India-A questionnaire based cross-sectional study. 2020.

16. Taghrir MH, Borazjani R, Shiraly R. COVID-19 and Iranian medical students; a survey on their related-knowledge, preventive behaviors and risk perception. Arch Iran Med. 2020;23:249-254. doi:10.34172/ aim. 2020.06

17. Modi PD, Nair G, Uppe A, et al. COVID-19 awareness among healthcare students and professionals in Mumbai metropolitan region: a questionnaire-based survey. Cureus. 2020;12. 10.7759/cureus.7514

18. Khader Y, Al Nsour M, Al-Batayneh OB, et al. Dentists' awareness, perception, and attitude regarding COVID-19 and infection control: cross-sectional study among Jordanian dentists. JMIR Public Health Surveill. 2020;6:e18798.

19. Bhagavathula AS, Aldhaleei WA, Rahmani J, Mahabadi MA, Bandari DK. Novel Coronavirus (COVID-19) knowledge and perceptions: a survey on healthcare workers. MedRxiv. 2020.

20. Bhagavathula AS, Aldhaleei WA, Rahmani J, Mahabadi MA, Bandari DK. Knowledge and perceptions of COVID-19 among health care workers: cross-sectional study. JMIR Public Health Surveill. 2020;6:e19160. 
21. Burki T. Understanding variants of SARS-CoV-2. Lancet. 2021;397:462. doi:10.1016/S0140-6736(21)00298-1

22. Rzymski P, Nowicki M, Mullin GE, et al. Quantity does not equal quality: scientific principles cannot be sacrificed. Int Immunopharmacol. 2020;86:106711. doi:10.1016/j.intimp.2020.106711

23. Omrani AS, Shalhoub S. Middle East respiratory syndrome coronavirus (MERS-CoV): what lessons can we learn? J Hosp Infect. 2015;91:188-196. doi:10.1016/j.jhin.2015.08.002

24. McEachan R, Taylor N, Harrison R, Lawton R, Gardner P, Conner M. Meta-analysis of the Reasoned Action Approach (RAA) to understanding health behaviors. Ann Behav Med. 2016;50:592-612. doi:10.1007/s12160-016-9798-4

25. Clarkson JRC, Richards D, Robertson C, Aceves-Martins M. Aerosol generating procedures and their mitigation in international dental guidance documents - a rapid review. Cochrane Oral Health. 2020.

26. Ge ZY, Yang LM, Xia JJ, Fu XH, Zhang YZ. Possible aerosol transmission of COVID-19 and special precautions in dentistry. J Zhejiang Univ Sci B. 2020;21:361-368. doi:10.1631/jzus.B2010010
27. Saqlain M, Munir MM, Rehman SU, et al. Knowledge, attitude, practice and perceived barriers among healthcare workers regarding COVID-19: a cross-sectional survey from Pakistan. J Hosp Infect. 2020;105:419-423. doi:10.1016/j.jhin.2020.05.007

28. Abdel Wahed WY, Hefzy EM, Ahmed MI, Hamed NS. Assessment of knowledge, attitudes, and perception of health care workers regarding COVID-19, a cross-sectional study from Egypt. J Community Health. 2020;45:1242-1251. doi:10.1007/s10900-02000882-0

29. Wang Y, McKee M, Torbica A, Stuckler D. Systematic literature review on the spread of health-related misinformation on social media. Soc Sci Med. 2019;240:112552. doi:10.1016/j. socscimed.2019.112552

30. Shimizu K. 2019-nCoV, fake news, and racism. Lancet. 2020;395:685-686. doi:10.1016/S0140-6736(20)30357-3
Journal of Multidisciplinary Healthcare

\section{Publish your work in this journal}

The Journal of Multidisciplinary Healthcare is an international, peerreviewed open-access journal that aims to represent and publish research in healthcare areas delivered by practitioners of different disciplines. This includes studies and reviews conducted by multidisciplinary teams as well as research which evaluates the results or conduct of such teams or healthcare processes in general. The journal

\section{Dovepress}

covers a very wide range of areas and welcomes submissions from practitioners at all levels, from all over the world. The manuscript management system is completely online and includes a very quick and fair peer-review system. Visit http://www.dovepress.com/testimonials. php to read real quotes from published authors. 